\title{
Article \\ Complexes of Transition Metals with Petroleum Porphyrin Ligands: Preparation and Evaluation of Catalytic Ability
}

\author{
Damir Tazeev, Lenar Musin (D), Nikolay Mironov*(D), Dmitry Milordov, Elvira Tazeeva, Svetlana Yakubova (D) \\ and Makhmut Yakubov (D)
}

check for

updates

Citation: Tazeev, D.; Musin, L.; Mironov, N.; Milordov, D.; Tazeeva,

E.; Yakubova, S.; Yakubov, M.

Complexes of Transition Metals with Petroleum Porphyrin Ligands: Preparation and Evaluation of Catalytic Ability. Catalysts 2021, 11 , 1506. https://doi.org/10.3390/ catal11121506

Academic Editor: Beatriz Royo

Received: 12 November 2021 Accepted: 7 December 2021 Published: 10 December 2021

Publisher's Note: MDPI stays neutral with regard to jurisdictional claims in published maps and institutional affiliations.

Copyright: (c) 2021 by the authors. Licensee MDPI, Basel, Switzerland. This article is an open access article distributed under the terms and conditions of the Creative Commons Attribution (CC BY) license (https:// creativecommons.org/licenses/by/ $4.0 /)$
FRC Kazan Scientific Center, Arbuzov Institute of Organic and Physical Chemistry, Russian Academy of Sciences, 420088 Kazan, Russia; tazeevexc4@yahoo.com (D.T.); 777lenar@list.ru (L.M.); milordoff@yandex.ru (D.M.); tazeeva_elvira@mail.ru (E.T.); yakubovasg@mail.ru (S.Y.); yakubovmr@mail.ru (M.Y.)

* Correspondence: n_mir@mail.ru

\begin{abstract}
In the present work, the first data on the catalytic activity of $d$-metal complexes of petroleum porphyrins obtained via two-stage re-metallization (acid demetallization with subsequent metalation) of high-purity petroleum vanadyl porphyrins are presented. During acid demetallization of petroleum vanadyl porphyrins, the highest yield (49\%) and spectral purity of free petroporphyrin bases were achieved with concentrated sulfuric acid and a diluted solution of vanadyl porphyrins in chloroform. In the series of divalent cations of $\mathrm{Mn}, \mathrm{Fe}, \mathrm{Co}, \mathrm{Ni}, \mathrm{Cu}$, and $\mathrm{Zn}$, only the last four metals are complexed with demetallated petroporphyrins without significant changes in their component composition, whereas the interaction with $\mathrm{Mn}$ and Fe cations causes an evident structural transformation or even full degradation of petroporphyrin macrocycles, respectively. The composition and spectral purity of petroleum porphyrin-containing reactants and products were analyzed by FT-IR, UV-Vis, NMR, and MALDI-TOF mass spectroscopic methods. The obtained petroporphyrin-based $d$-metal complexes were assayed by the reaction of 2-mercaptoethanol oxidative dimerization, in which the copper porphyrins exhibited the highest catalytic activity.
\end{abstract}

Keywords: vanadyl porphyrins; re-metallization; petroporphyrin-based catalyst; Merox; heavy oil

\section{Introduction}

In living nature, porphyrins are found in prosthetic groups of proteins and enzymes responsible for the processes of aerobic oxidation, oxygen transport, and peroxide destruction [1-3]. Based on synthetic porphyrins, effective biomimetic catalysts for the processes of epoxidation, sulfoxidation, demercaptanization, hydroxylation, carbonylation, etc. have been developed [2-4]. Despite the great importance of these reactions for chemical industry, synthetic porphyrins have not found significant practical application on an industrial scale. Instead of them, synthetic phthalocyanines, as readily accessible and low-cost analogs of porphyrins, have received widespread application [1]. However, besides synthetic and natural porphyrins, there is another class of these compounds whose applied potential has not yet been evaluated. This is the fossil porphyrins (or petroporphyrins) found in heavy oils with high vanadium content. The petroporphyrin content in this kind of fossil raw material can reach $0.1 \%$, which makes the heavy oil a promising source for the production of petroporphyrins on the industrial scale.

Petroporphyrins are mainly represented by vanadyl and nickel complexes, with a large predominance of the former $[5,6]$. The petroporphyrin macrocyclic ligand is mainly represented by such structural types as etio-, deoxophylloerythroetio- (DPEP), dicyclic-deoxophylloerythroetioporphyrins (di-DPEP), and their rhodo-derivatives [5,6]. Etioporphyrins are porphin derivatives with alkyl substituents at the $\beta$-positions of the pyrrole fragments. DPEP- and di-DPEP-type porphyrins have, respectively, one and two exocyclic alkylene groups attached to neighboring meso- and $\beta$-positions. Rhodo-derivatives of etio, DPEP, and di-DPEP porphyrins contain an aromatic ring fused with a tetrapyrrole 
macrocycle $[5,6]$. The minor representatives of the petroporphyrins include the complexes with nitrogen- and oxygen-bearing substituents as well as with additional condensed heterocycles [6]. Petroleum porphyrins attract great fundamental interest, as the elucidation of their structure, distribution, and contribution to asphaltene aggregation behavior can shed light on the issues of petroleum genesis and maturation and colloidal properties [5,6].

Due to the presence of vanadium and nickel, petroporphyrins may cause significant detrimental effects in petroleum refining processes [6,7]. The development of technologies for petroporphyrin isolation from heavy oil feedstocks can help solve some problems concerning heavy oil upgrading and will open up for the industry an access to low-cost petroporphyrins as an alternative to synthetic phthalocyanines widely used in catalysis, medicine, optical and electronic devices, etc. [1,8-10]. Laboratory-scale methods for petroporphyrin isolation and deep purification are already developed [11,12]. To assess the advisability of creating the industry-scale methods of petroporphyrin production, it is necessary to study their practically useful properties relevant to the industry.

One of the most demanded industrial applications of metal phthalocyanines is their use as catalysts in the oxidative demercaptanization process [13-15], often named in the literature as the Merox reaction. In this reaction, metal phthalocyanines behave as biomimetic catalysts (inorganic mimics of cytochrome P450), because they are capable of limited oxidation of mercaptans into disulfides by molecular oxygen under mild conditions. The catalytic oxidative demercaptanization is widely used for eliminating offensive odors from industrial wastewaters and petroleum products $[14,16]$ and to reduce the corrosion activity of mercaptans in motor fuel [15]. The Merox process was used in the present work as a model reaction to compare the catalytic performance of transition metal complexes of petroleum porphyrins, synthesized for the first time from high-purity petroleum vanadyl porphyrins obtained by the sulfocationite-based chromatographic method [11].

\section{Results and Discussion}

High-purity petroleum vanadyl porphyrins, used in the present work as a starting material for the synthesis of metalloporphyrin catalysts, were isolated from $\mathrm{N}, \mathrm{N}$ dimethylformamide extract of heavy oil asphaltenes by the sulfocationite-based chromatographic method as described in our recent work [11]. To reveal the best reaction conditions for vanadyl porphyrin demetallation, four different experiments were carried out, two of which were adopted from the literature with minor modifications. In the first two experiments, $98 \%$ sulfuric acid was used as a demetallation agent, while the reactions were conducted at different temperatures (under water-ice cooling and at room temperature). Since it was pre-established that concentrated sulfuric acid destroys solid petroleum vanadyl porphyrins, the latter were pre-dissolved in chloroform before exposure to the acid. In the two other experiments, either methanesulfonic acid or a 1:4 mixture of sulfuric and trifluoroacetic acids, as milder demetallation agents, were used $[17,18]$. According to the literature methods $[17,18]$, reactions with these demetallation agents were conducted at 130 and $100^{\circ} \mathrm{C}$, respectively, using powdered vanadyl porphyrins.

The results of demetallation were monitored by UV-Vis spectroscopy (Figure 1). A slight blue-shift of the Soret band from 408 to $397 \mathrm{~nm}$ as well as the appearance of four Q-bands-characteristic of demetallated petroleum porphyrins-in place of the two $\alpha$ - and $\beta$-bands of the initial vanadyl porphyrins [5], indicate that demetallation occurs in all four cases. Based on the background absorption level in Figure 1, the least pure product was obtained upon demetallation with methanesulfonic acid. Much purer demetallated petroleum porphyrins were obtained upon treatment with sulfuric acid, especially upon cooling of the reaction mixture or dilution of sulfuric acid by weak trifluoroacetic acid. This is probably due to the fact that stronger sulfuric acid makes it possible to reduce the reaction time from several hours, in the case of methanesulfonic acid [17], to 5-30 min, thus decreasing the possibility of by-product formation. Free porphyrin bases obtained under such conditions possess a spectral purity comparable to that of synthetic octaethyletioporphyrin (Figure 1). We find the demetallation under $\mathrm{CHCl}_{3} / \mathrm{H}_{2} \mathrm{SO}_{4} / 0{ }^{\circ} \mathrm{C}$ conditions 
preferable to that under $\mathrm{H}_{2} \mathrm{SO}_{4} / \mathrm{CF}_{3} \mathrm{COOH} / 100{ }^{\circ} \mathrm{C}$ ones, because the first reaction proceeds under milder conditions and provides higher yield of the free porphyrin bases ( $49 \mathrm{vs} .31 \%$ ). The main product loss occurs at the workup procedure (extraction of the product from the reaction mixture neutralized with aq. $\mathrm{NaOH}$ ), in which the sodium trifluoroacetate behaves as a weak surfactant stabilizing the water-chloroform emulsion, which absorbs a significant part of the product. All further studies described below were conducted with petroleum porphyrins demetallated under $\mathrm{CHCl}_{3} / \mathrm{H}_{2} \mathrm{SO}_{4} / 0{ }^{\circ} \mathrm{C}$ conditions.



Figure 1. UV-Vis spectra of demetallized petroleum porphyrins obtained with methanesulfonic (blue), sulfuric at $\mathrm{rt}$ (red) and at $0{ }^{\circ} \mathrm{C}$ (purple), and 1:4 mixture of sulfuric and trifluoroacetic acids (green). Dashed line is the absorbance of synthetic octaethyletioporphyrins of $97 \%$ purity. The inset is the UV-Vis spectrum of the initial petroleum vanadyl porphyrins. All spectra were registered in chloroform.

FT-IR spectroscopy confirms the conclusion about the acid demetallization of petroleum vanadyl porphyrins, since a broad band in the region of $\sim 3400 \mathrm{~cm}^{-1}$ corresponding to the valence vibrations of pyrrolic $\mathrm{N}-\mathrm{H}$ bonds appears in the spectrum of the product (Figure 2). MALDI-TOF analysis indicates the full completeness of demetallization, because there are no signals of the initial vanadyl porphyrins in the mass spectrum of the product (Figure 3). The signals of demetallated porphyrins are shifted toward lower masses relative to the initial vanadyl porphyrins. The shift value is $m / z 65$, which corresponds to the loss of vanadyl cations $\left(\mathrm{VO}^{2+}, 67 \mathrm{~g} / \mathrm{mol}\right)$ followed by further attachment of two protons to the nitrogen atoms of pyrroles. On both mass spectra, the same homological series of $C_{27}-C_{42}$ porphyrins with the most abundant $C_{32}$ DPEP type $(\mathrm{m} / z 541$ and 476 in the cases of vanadyl and demetallated porphyrins, respectively) are identified. The quantitative composition of the main types of porphyrins undergoes insignificant changes during demetallization mainly due to the reduction in the content of rhodo porphyrins and an increase in the proportion of DPEP-type porphyrins (Figure 3). It was reported in previous work [6] that petroporphyrin demetallation can be accompanied by changes in their component composition. According to the mass spectrum, the number average molecular weight $\left(M_{n}\right)$ of demetallated porphyrins is equal to $500.6 \mathrm{~g} / \mathrm{mol}$, which is $65 \mathrm{~g} / \mathrm{mol}$ less than that of the initial petroleum vanadyl porphyrins [19].

Metallation of the free petroporphyrin bases was attempted using $\mathrm{M}_{\mathrm{x}}(\mathrm{OAc})_{\mathrm{y}}$ salts, where $\mathrm{M}$ is $\mathrm{Cr}^{3+}, \mathrm{Mn}^{2+}, \mathrm{Fe}^{2+}, \mathrm{Co}^{2+}, \mathrm{Ni}^{2+}, \mathrm{Cu}^{2+}$, and $\mathrm{Zn}^{2+}$. Complexation with copper and zinc cations was carried out in a methanol-chloroform mixture at room temperature (addition of methanol provided sufficient solubility of the salt). Due to the poor solubility of cobalt acetate in the alcohol, its complexation with the porphyrins was carried out in acetic acid. For complexation with manganese and nickel, more severe reaction conditions were required (heating to $100{ }^{\circ} \mathrm{C}$ and higher), and so the reactions with these metals were conducted in DMF. No bands of demetallated petroleum porphyrins were detected in the UV-Vis spectra of manganese, cobalt, nickel, copper, and zinc porphyrins, which indicates complete metallation of the initial petroporphyrin bases. In the ${ }^{1} \mathrm{H}$ NMR spectra registered 
for copper and cobalt porphyrins, no signals of pyrrolic $\mathrm{N}-\mathrm{H}$ protons were observed either. We did not detect complex formation with $\mathrm{Cr}^{3+}$, since the UV-Vis spectrum of the reaction mixture remained unchanged irrespective of the reaction conditions (temperature, solvent). Interaction with iron(II) acetate resulted in complete destruction of the petroporphyrin macrocycles, as detected by disappearance of the Soret band and simultaneous growth of the background absorbance on the UV-Vis spectrum of the reaction mixture. The marginal formation of the iron complexes, accompanied by simultaneous destruction of the porphyrin ligands, only occurred when iron(II) chloride salt was used instead of the acetate. Due to the low spectral yield and possible problems with purification, the iron complexes were not isolated and studied in this work.

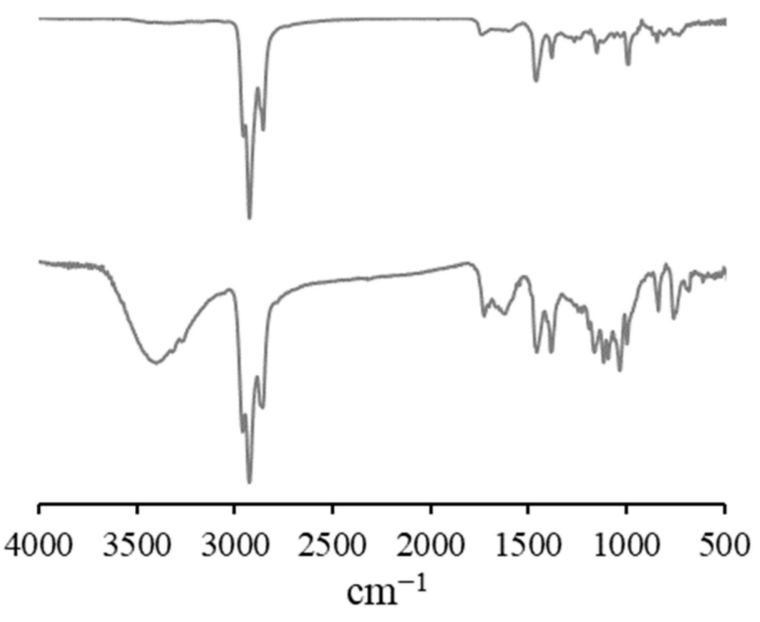

Figure 2. FT-IR spectra of the initial petroleum vanadyl porphyrins (top) and of their free porphyrin bases (bottom).



Figure 3. MALDI-TOF mass spectra of demetallated (top) and initial vanadyl petroleum porphyrins (bottom) and their component compositions (in \%).

The identification of the synthesized metalloporphyrins by their UV-Vis spectra is possible for nickel porphyrins only, because they, along with vanadyl porphyrins, are the minor petroleum components and were already described in the literature. The absorption maxima in the UV-Vis spectra of the nickel petroporphyrins $\left(\lambda_{\max }=392,512,553 \mathrm{~nm}\right)$ synthesized in the present work coincide with the literature values within $\pm 2 \mathrm{~nm}[17,20,21]$, which excludes any doubts as to the product composition. Complexes with such metals as $\mathrm{Mn}^{2+}, \mathrm{Cu}^{2+}$, and $\mathrm{Zn}^{2+}$ were also identified among fossil porphyrins [22,23]. However, their UV-Vis spectra cannot be registered, since these metalloporphyrins are the trace petroleum components detectable using ultra-high resolution mass spectrometric methods only. Therefore, the only available way to identify manganese, cobalt, copper, and zinc porphyrins synthesized in the present work is mass spectrometry (Figure 4). 

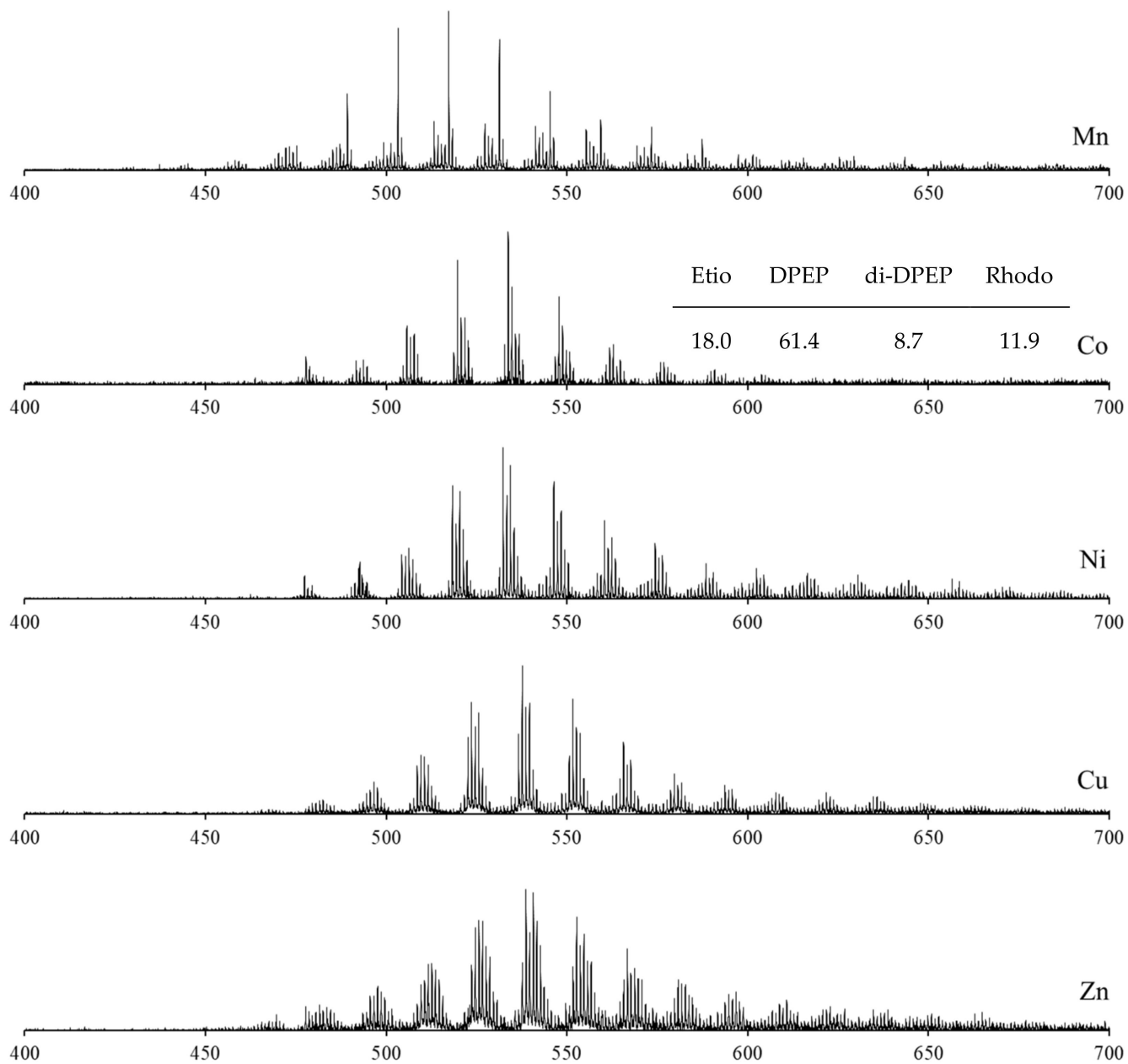

Figure 4. MALDI-TOF mass spectra of petroleum metalloporphyrin complexes synthesized in the present work.

The mass spectra of cobalt, nickel, copper, and zinc porphyrins are shifted toward higher masses compared to the spectrum of the initial demetallated porphyrins (Figure 3) by the atomic weight of the metal minus the mass of two substituting pyrrole protons. As in the case of demetallated petroleum porphyrins, the most abundant molecular ion $[\mathrm{M}]^{+\bullet}$ of cobalt, nickel, copper, and zinc porphyrins corresponds to the $\mathrm{C}_{32}$-DPEP homolog $(m / z 533,532,537$, and 538, respectively). The number of homologs visible on the mass spectra varies depending on the metal $\left(C_{28}-C_{38}, C_{28}-C_{42}, C_{28}-C_{40}\right.$, and $C_{27}-C_{41}$ for cobalt, nickel, copper, and zinc porphyrins, respectively), which is probably explained by nonequal response of various metalloporphyrins toward UV laser-induced desorption and ionization. In addition, in the series of cobalt-nickel-copper-zinc, an increase in the number of peaks within the group of metalloporphyrins with the same number of carbon atoms is noted, which is explained by the increase in the number of stable isotopes in this series of metals. Thus, it is known that cobalt consists of one stable isotope, ${ }^{59} \mathrm{Co}$; nickel consists of two major isotopes, ${ }^{58} \mathrm{Ni}(68.08 \%)$ and ${ }^{60} \mathrm{Ni}(26.22 \%)$; copper consists of two isotopes, ${ }^{63} \mathrm{Cu}(69.2 \%)$ and ${ }^{65} \mathrm{Cu}(30.8 \%)$; and zinc consists of three major isotopes, ${ }^{64} \mathrm{Zn}(48.6 \%),{ }^{66} \mathrm{Zn}(27.9 \%)$, and ${ }^{68} \mathrm{Zn}(18.8 \%)$. No signals of demetallated petroporphyrins are detected in the mass spectra of cobalt, nickel, copper, and zinc porphyrins (Figure 4), which is in line with the FT-IR measurements showing the disappearance of the $v_{\mathrm{N}-\mathrm{H}}$ band in the spectra of these metalloporphyrins (Figure 5). The component composition of cobalt complexes (Figure 4) does not undergo significant changes compared to the initial demetallated porphyrins (Figure 3). Minor perturbations in the composition can be explained by the higher coordinating ability of DPEP and rhodo porphyrins toward $\mathrm{Co}^{2+}$ 
cations compared to their etio and di-DPEP counterparts. The component compositions of nickel, copper, and zinc porphyrins were not calculated, due to strong interference with isotopic peaks.

Preparation of manganese complexes is accompanied by a dramatic change in the group composition of petroporphyrins (Figure 4). The mass spectrum of manganese porphyrins shows a manifold decrease in the intensity of DPEP porphyrins, which dominate both in the initial objects (Figure 3) and in the synthesized cobalt, nickel, copper, and zinc petroleum porphyrins (Figure 4). The components with $m / z 475+14 n$, where $n$ is $0-12$, become the most abundant instead of DPEP porphyrins, and these $m / z$ values formally correspond to etio porphyrins. Possible structures with such $\mathrm{m} / z$ values are shown in Scheme 1.

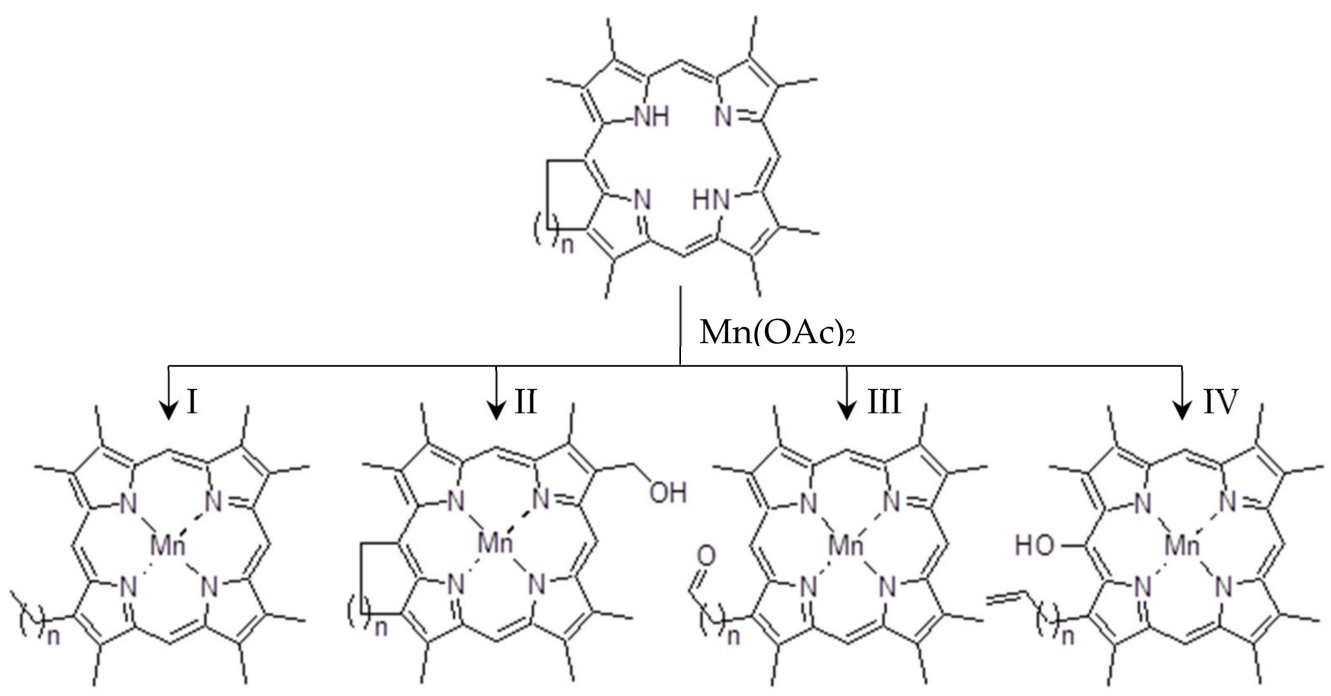

Scheme 1. Possible ways of DPEP porphyrin transformation in reaction with $\mathrm{Mn}(\mathrm{OAc})_{2}$ (the position of substituents is arbitrary).

Direct transformation of DPEP porphyrins into etio (pathway I) seems the least feasible, because an alkene should be formed during simple C-C bond cracking [24]. Oxidation of peripheral substituents (pathway II) also looks improbable, since in this case the signals of oxidized etioporphyrins would have appeared in the mass spectrum. Pathway III would lead to the appearance of a strong $v_{\mathrm{C}=\mathrm{O}}$ band in the $\sim 1700 \mathrm{~cm}^{-1}$ region of the FT-IR spectrum, which is not actually observed (Figure 5). Finally, pathway IV (isocyclic ring cleavage resulting in alkenyl and hydroxyl groups formation) does not contradict either the mass spectrum or the FT-IR spectrum, where a broad band of $v_{\mathrm{OH}}$ vibrations $\left(\sim 3400 \mathrm{~cm}^{-1}\right)$ appeared. Thus, pathway IV should be regarded as the most probable, but it is possible that more deeply oxidized structures are formed which are separated from the main product during chromatographic purification. The shift of the molecular weight distribution of manganese porphyrins relative to other metalloporphyrins (Figure 4) is most likely a result of additional purification on silica.

The synthesized petroleum metalloporphyrins were further assayed in the Merox reaction, consisting in oxidation of mercaptan to disulfide. As a mercaptan, water-soluble 2-mercaptoethanol was chosen. Water-insoluble metalloporphyrins were introduced into the reaction, being immobilized onto silica gel. Immobilization served to increase the contact area between the catalyst and substrate and to facilitate the catalyst's separation from the reaction mixture. The $\mathrm{pH}$ of the reaction medium was adjusted to 9.0 in accordance with the work [14], where the highest rate of 2-mercaptoethanol oxidation by cobalt phthalocyanine was achieved at $\mathrm{pH}$ 8.5-9.0. In [14], the 2-mercaptoethanol dimerization rate in response to mercaptan concentration, catalyst loading, and oxygen pressure was also studied. In this work, we set these parameters so that incomplete conversion of the reactant occurred within the time of reaction $(30 \mathrm{~min})$. This allows us to express the cat- 
alytic activity of metalloporphyrins through the ratio of the chromatographic peak areas of 2,2'-dithiobisethanol (product) and unreacted 2-mercaptoethanol. The results of catalytic experiments are summarized in Table 1. In addition to the synthesized petroleum metalloporphyrins, the initial vanadyl porphyrins were also tested, and six control experiments were conducted to ensure the importance of the ligand framework and reaction conditions for catalytic performance.



Figure 5. FT-IR spectra of synthesized petroleum metalloporphyrins.

Table 1. Catalytic activity of petroleum metalloporphyrins in the Merox reaction ${ }^{1}$ expressed as the ratio of the chromatographic peak areas of the product $\left(\mathrm{S}^{\mathrm{RSSR}}\right)$ and unreacted reactant $\left(\mathrm{S}^{\mathrm{RSH}}\right)$.

\begin{tabular}{|c|c|c|c|c|c|}
\hline Entry & Catalyst & $\mathrm{S}^{\mathrm{RSSR}} / \mathrm{S}^{\mathrm{RSH}}$ & Entry & Catalyst & $\mathrm{S}^{\mathrm{RSSR}} / \mathrm{S}^{\mathrm{RSH}}$ \\
\hline 1 & VO(II)Ps & 0.14 & 8 & $\mathrm{Co}(\mathrm{II}) \mathrm{Ps}^{3}$ & 0 \\
\hline 2 & Mn(II)Ps & 0.20 & 9 & $\mathrm{Co}(\mathrm{OAc})_{2}$ & n.d. 4 \\
\hline 3 & $\mathrm{Co}(\mathrm{II}) \mathrm{Ps}$ & 1.20 & 10 & $\mathrm{Cu}(\mathrm{OAc})_{2}$ & n.d. 5 \\
\hline 4 & Ni(II)Ps & 0.51 & 11 & free $\mathrm{SiO}_{2} 6$ & 0 \\
\hline 5 & $\mathrm{Cu}(\mathrm{II}) \mathrm{Ps}$ & 9.11 & 12 & no catalyst & 0 \\
\hline 6 & $\mathrm{Zn}(\mathrm{II}) \mathrm{Ps}$ & 0.26 & 13 & no oxygen ${ }^{7}$ & 0 \\
\hline 7 & $\mathrm{Co}(\mathrm{II}) \mathrm{Ps}^{2}$ & 0 & & & \\
\hline
\end{tabular}

${ }^{1}$ Reaction conditions: 2-mercaptoethanol (5 g/L), aq. borate buffer (100 mL, $\left.\mathrm{pH} 9.0\right)$, gaseous oxygen (1 atm), petroleum porphyrin-based catalyst immobilized onto silica gel $(300 \mathrm{mg}), 40{ }^{\circ} \mathrm{C}, 30 \mathrm{~min} .{ }^{2}$ In deionized water without buffer addition. ${ }^{3}$ In $\mathrm{CHCl}_{3}$ without buffer addition and use of $\mathrm{SiO}_{2}$ support for the catalyst. ${ }^{4}$ Not determined, because no reactant or product was detected. ${ }^{5}$ Not determined, because no reactant and only trace amount of product were detected. ${ }^{6}$ Without metalloporphyrin loading. ${ }^{7}$ In argon atmosphere.

After 30 min stirring, both 2,2'-dithiobisethanol and 2-mercaptoethanol were detected in the reaction mixtures for the entries 1-6 only (Table 1). Copper porphyrins (entry 5) exhibited the highest catalytic activity, being much ahead of the cobalt porphyrins (entry 3). It is worthy of note that synthetic cobalt phthalocyanines were revealed in the 
literature to be the most active in the Merox process compared to iron, nickel, and copper complexes $[25,26]$. When the reaction was conducted without alkaline buffer (entry 7) and under homogeneous conditions in chloroform (entry 8), only the peak of unreacted 2-mercaptoethanol was detected by GCMS. This is consistent with a number of other studies which established that metalloporphyrin-catalyzed mercaptan dimerization proceeds only in alkaline media [14]. No product formation was observed in the absence of metal catalysts or under inert atmosphere (entries 11-13). Neither 2,2'-dithiobisethanol nor 2-mercaptoethanol were detected in the reaction mixture when cobalt acetate was used as a catalyst (entry 9). Most probably, cobalt acetate promotes more intense mercaptan oxidation to sulfonate, not extractable with chloroform and not detectable by GCMS without preliminary derivatization to ester. The same full conversion of 2-mercaptoethanol was observed with copper acetate (entry 10), however a trace amount of the dimer was detected in this case. Thus, only the metalloporphyrin complexes provide limited oxidation of the mercaptan to the desired disulfide.

Possible reaction pathways of the Merox process were discussed in detail elsewhere $[27,28]$. Regardless of the particular mechanism proposed, it is believed that the metal acts as a shuttle redox mediator for electron transfer from the $\mathrm{RS}^{-}$anion to the coordinated $\mathrm{O}_{2}$ molecule.

\section{Materials and Methods}

\subsection{Materials}

Solvents (chloroform, dichloromethane, N,N-dimethylformamide (DMF), methanol), acids (sulfuric, methanesulfonic, trifluoroacetic, acetic), salts $\left(\mathrm{M}(\mathrm{OAc})_{2} \cdot 4 \mathrm{H}_{2} \mathrm{O}\right.$, where $\mathrm{M}=\mathrm{Mn}^{2+}, \mathrm{Fe}^{2+}, \mathrm{Co}^{2+}, \mathrm{Ni}^{2+}, \mathrm{Cu}(\mathrm{OAc})_{2} \cdot \mathrm{H}_{2} \mathrm{O}, \mathrm{Zn}(\mathrm{OAc})_{2} \cdot 2 \mathrm{H}_{2} \mathrm{O}$, and $\left.\mathrm{Cr}(\mathrm{OAc})_{3} \cdot \mathrm{H}_{2} \mathrm{O}\right)$, and 2-mercaptoethanol were of reagent grade purity and were used without further purification. Synthetic octaethyletioporphyrin $(2,3,7,8,12,13,17$-octaethyl-21H,23H-porphine) of $97 \%$ purity was purchased from Aldrich. The borate buffer was composed of $\mathrm{H}_{3} \mathrm{BO}_{3}, \mathrm{KCl}$, and $\mathrm{NaOH}$ taken at 1:1:0.4 molar ratio. As a stationary phase for column chromatography and a solid support for the immobilization of metalloporphyrin catalysts, an activated mesoporous silica gel with an average pore size of $90 \AA$ (data from supplier) was used. Silica gel was dried for $5 \mathrm{~h}$ at $150{ }^{\circ} \mathrm{C}$ prior to use. High-purity vanadyl porphyrins were derived from $\mathrm{N}, \mathrm{N}$-dimethylformamide extract of asphaltenes of heavy oil from Smorodinskoe oilfield (Russian Federation) as described in our previous work [11].

\subsection{Demetallization of Petroleum Vanadyl Porphyrins}

To select the best demetallization procedure, four test experiments with different reaction conditions, displayed in Table 2, were carried out. In each experiment, $10 \mathrm{~mL}$ of acid was poured into a $100 \mathrm{~mL}$ round-bottom flask, and $20 \mathrm{mg}$ of high-purity petroleum vanadyl porphyrins was added either as a powder or as a solution in $20 \mathrm{~mL}$ of chloroform. The reaction mixture was stirred on a magnetic stirrer under inert atmosphere at the indicated temperature and time (Table 2) and then diluted with $50 \mathrm{~mL}$ of ice water. The excess acid was neutralized with aq. $\mathrm{NaOH}$ until slightly alkaline $(\mathrm{pH} \sim 8$ as detected by indicator paper), and the precipitated free porphyrin bases were extracted with chloroform $(2 \times 30 \mathrm{~mL})$. The demetallated porphyrins dissolved in chloroform were washed several times with deionized water, and the solvent was distilled off on a rotary evaporator. The highest yield of spectrally pure free porphyrin bases was obtained by demetallization with cold sulfuric acid in chloroform (Table 2). This method was used for further production of the required amounts of demetallated porphyrins.

UV-Vis, $\mathrm{CHCl}_{3}, \lambda_{\max }(\mathrm{nm}): 397,499,533,566,621$.

${ }^{1} \mathrm{H}$ NMR $\left(500 \mathrm{MHz}, \mathrm{CDCl}_{3}\right): \delta$ 0.98-1.88 $(23 \mathrm{H}$, br m, CH3), 3.48-4.07 $(16 \mathrm{H}, \mathrm{br} \mathrm{m}$, -CH2-), 5.13 (3H, br s, -CH=C-), 9.96 (2H, br s, N-H) ppm. 
Table 2. Reaction conditions for demetallization of petroleum vanadyl porphyrins.

\begin{tabular}{|c|c|c|c|c|c|c|}
\hline \multirow{2}{*}{ № } & \multirow{2}{*}{ Acid } & \multirow{2}{*}{ Solvent } & \multirow{2}{*}{$\mathrm{T},{ }^{\circ} \mathrm{C}$} & \multirow{2}{*}{$\mathbf{t}, \min$} & \multicolumn{2}{|c|}{ Yield } \\
\hline & & & & & in $\mathrm{mg}{ }^{1}$ & in $\%$ \\
\hline $1^{2}$ & $\mathrm{H}_{2} \mathrm{SO}_{4}$ & $\mathrm{CHCl}_{3}$ & 25 & 5 & - & - \\
\hline 2 & $\mathrm{H}_{2} \mathrm{SO}_{4}$ & $\mathrm{CHCl}_{3}$ & 0 & 5 & 8.8 & 49 \\
\hline $3^{2}$ & $\mathrm{CH}_{3} \mathrm{SO}_{3} \mathrm{H}$ & - & 130 & 240 & - & - \\
\hline 4 & $\begin{array}{c}\mathrm{H}_{2} \mathrm{SO}_{4} / \mathrm{CF}_{3} \mathrm{COOH} \\
(1: 4)\end{array}$ & - & 100 & 30 & 5.6 & 31 \\
\hline
\end{tabular}

${ }^{1}$ From $20 \mathrm{mg}$ of the initial vanadyl porphyrins. ${ }^{2}$ Yield was not calculated, because the spectral purity of the product was significantly lower than that of the synthetic octaethyletioporphyrin.

\subsection{Metallation of Petroleum Porphyrins}

\subsubsection{Petroleum Copper and Zinc Porphyrins}

Demetallized petroleum porphyrins $\left(20 \mathrm{mg}, 0.04 \mathrm{mmol}, M_{\mathrm{n}}=500.6 \mathrm{~g} / \mathrm{mol}\right)$ were dissolved in chloroform (30 mL). A tenfold molar excess of copper or zinc acetate (80 and $88 \mathrm{mg}$, respectively, $0.4 \mathrm{mmol})$ was mixed with a small amount of methanol $(3 \mathrm{~mL})$ and added to the porphyrin solution. The reaction mixture was stirred at room temperature for $4 \mathrm{~h}$, after which it was washed with deionized water to remove unreacted salt and concentrated on a rotary evaporator.

${ }^{1} \mathrm{H}$ NMR $\left(500 \mathrm{MHz}, \mathrm{CDCl}_{3}\right)$ for copper porphyrins: $\delta 0.76-1.30(23 \mathrm{H}, \mathrm{br} \mathrm{m}, \mathrm{CH} 3), 1.58$ $(16 \mathrm{H}$, br m, -CH2-), 4.24 (3H, br m, -CH=C-) ppm.

\subsubsection{Petroleum Cobalt Porphyrins}

Demetallized petroleum porphyrins $\left(20 \mathrm{mg}, 0.04 \mathrm{mmol}, M_{\mathrm{n}}=500.6 \mathrm{~g} / \mathrm{mol}\right)$ were dissolved in $\mathrm{AcOH}(30 \mathrm{~mL})$. $\mathrm{Co}(\mathrm{OAc})_{2} \cdot 4 \mathrm{H}_{2} \mathrm{O}(30 \mathrm{mg}, 0.12 \mathrm{mmol})$ was added to the porphyrin solution, which was then stirred at room temperature for $4 \mathrm{~h}$. When the reaction finished, the product was extracted with chloroform $(2 \times 20 \mathrm{~mL})$, washed with deionized water, and concentrated.

${ }^{1} \mathrm{H}$ NMR $\left(500 \mathrm{MHz}, \mathrm{CDCl}_{3}\right): \delta 0.88-1.30(23 \mathrm{H}, \mathrm{br} \mathrm{m}, \mathrm{CH} 3), 1.35-1.49(16 \mathrm{H}, \mathrm{br} \mathrm{m}$, -CH2-), 4.02-4.07 (3H, br m, -CH=C-) ppm.

\subsubsection{Petroleum Nickel Porphyrins}

Demetallized petroleum porphyrins $\left(20 \mathrm{mg}, 0.04 \mathrm{mmol}, M_{\mathrm{n}}=500.6 \mathrm{~g} / \mathrm{mol}\right)$ were dissolved in DMF $(30 \mathrm{~mL})$. $\mathrm{Ni}(\mathrm{OAc})_{2} \cdot 4 \mathrm{H}_{2} \mathrm{O}(31 \mathrm{mg}, 0.125 \mathrm{mmol})$ was added to the porphyrin solution, which was then stirred under reflux for $6 \mathrm{~h}$. When the reaction finished, the solvent was distilled off on a rotary evaporator; the product was dissolved in chloroform $(20 \mathrm{~mL})$, washed with deionized water, and concentrated.

\subsubsection{Petroleum Manganese Porphyrins}

Demetallized petroleum porphyrins $\left(20 \mathrm{mg}, 0.04 \mathrm{mmol}, M_{\mathrm{n}}=500.6 \mathrm{~g} / \mathrm{mol}\right)$ were dissolved in $\mathrm{DMF}(30 \mathrm{~mL}) . \mathrm{Mn}(\mathrm{OAc})_{2} \cdot 4 \mathrm{H}_{2} \mathrm{O}(98 \mathrm{mg}, 0.4 \mathrm{mmol})$ was added to the porphyrin solution, which was then stirred at $100{ }^{\circ} \mathrm{C}$ for $4 \mathrm{~h}$. When the reaction finished, the solvent was distilled off on a rotary evaporator; the product was dissolved in chloroform $(20 \mathrm{~mL})$, washed with deionized water, and concentrated. The crude product was further purified on the silica gel column using chloroform as eluent.

The spectral characteristics of the synthesized metalloporphyrins are shown in Table 3.

The number average molecular weights $\left(M_{n}\right)$ of the obtained products, as well as their measured metal and calculated metalloporphyrin contents, are summarized in Table 4. A small mismatching between experimental and calculated metal contents can be explained by some inaccuracy in $M_{\mathrm{n}}$ determination by the mass spectrometric method or by minor contamination of the products. The $M_{\mathrm{n}}$ values were computed by the known formula:

$$
M_{\mathrm{n}}=\Sigma_{i} I_{i} M_{\mathrm{i}} / \Sigma_{i} I_{i},
$$


where $I_{i}$ is the intensity of the $i$-peak on the MALDI-TOF mass spectrum and $M_{\mathrm{i}}$ is its $m / z$ value.

Table 3. UV-Vis data of petroleum metalloporphyrins synthesized in the present work.

\begin{tabular}{cccc}
\hline \multirow{2}{*}{ M(II)Ps } & \multicolumn{3}{c}{$\lambda_{\max }(\mathbf{n m})$ in $\mathbf{C H C l}_{\mathbf{3}}$} \\
\cline { 2 - 4 } & Soret & $\boldsymbol{\beta}$-Band & $\boldsymbol{\alpha}$-Band \\
\hline Mn(II)Ps & 414 & 580 & 590 \\
Co(II)Ps & 412 & 578 & 592 \\
Ni(II)Ps & 392 & 512 & 553 \\
Cu(II)Ps & 398 & 524 & 563 \\
Zn(II)Ps & 401 & 531 & 567 \\
\hline
\end{tabular}

Table 4. Composition of petroporphyrin products synthesized in the present work.

\begin{tabular}{|c|c|c|c|c|}
\hline \multirow{2}{*}{ M(II)Ps } & \multirow{2}{*}{$M_{\mathrm{n}}, \mathrm{g} / \mathrm{mol}$} & \multicolumn{2}{|c|}{ Metal Content, wt.\% } & \multirow{2}{*}{$\begin{array}{c}\text { M(II)Ps } \\
\text { Content, }{ }^{3} \text { wt. } \%\end{array}$} \\
\hline & & Calculated $^{1}$ & Experimental $^{2}$ & \\
\hline $\mathrm{H}_{2}(\mathrm{II}) \mathrm{Ps}$ & 500.6 & - & - & - \\
\hline Mn(II)Ps & 549.1 & 10.0 & $8.36 \pm 0.40$ & 83.6 \\
\hline $\mathrm{Co}(\mathrm{II}) \mathrm{Ps}$ & 550.8 & 10.7 & $9.59 \pm 0.31$ & 89.6 \\
\hline $\mathrm{Ni}(\mathrm{II}) \mathrm{Ps}$ & 563.8 & 10.4 & $9.68 \pm 0.24$ & 92.7 \\
\hline $\mathrm{Cu}(\mathrm{II}) \mathrm{Ps}$ & 563.0 & 11.3 & $10.30 \pm 0.29$ & 91.3 \\
\hline $\mathrm{Zn}(\mathrm{II}) \mathrm{Ps}$ & 558.2 & 11.7 & $10.25 \pm 0.42$ & 87.5 \\
\hline
\end{tabular}

${ }^{1}$ Based on $M_{n}$ values. ${ }^{2}$ As measured by graphite furnace atomic absorption spectrometry. ${ }^{3}$ Based on calculated and experimental metal contents.

\subsection{Immobilization of Metalloporphyrins on Silica Gel}

$10 \mathrm{mg}$ of metalloporphyrins was dissolved in $3 \mathrm{~mL}$ of chloroform; $300 \mathrm{mg}$ of mesoporous silica gel was added, and the solvent was slowly evaporated on a vacuum pump at room temperature.

\subsection{Catalytic Demercaptanization}

In a thick-walled glass reactor, a solution of 2-mercaptoethanol $(500 \mathrm{mg})$ in deionized water $(100 \mathrm{~mL})$ was prepared. The $\mathrm{pH}$ of the solution was adjusted to 9.0 using borate buffer. To the resulting solution, a $\mathrm{SiO}_{2}$-immobilized catalyst $(300 \mathrm{mg}$ ) was added, and the reactor was connected to an oxygen cylinder. The reaction mixture was stirred at $40{ }^{\circ} \mathrm{C}$ and an oxygen pressure of $1 \mathrm{~atm}$ for $30 \mathrm{~min}$. After this time, the catalyst was filtered off from the reaction mixture, after which the product and unreacted reactant were extracted with dichloromethane $(3 \times 50 \mathrm{~mL})$. The organic solution was concentrated to a volume of $10 \mathrm{~mL}$ and analyzed on GCMS.

\subsection{Equipment}

UV-Vis absorption spectra were recorded on a PE-5400UF spectrometer (Ekroskhim, Russia) equipped with a pair of $1 \mathrm{~cm}$ path length quartz cells. FT-IR spectra of porphyrin thin films coated on $\mathrm{KBr}$ disks were recorded on a Spectrum One spectrometer (PerkinElmer, USA). Metal content was analyzed on a graphite furnace atomic absorption spectrophotometer MGA-1000 (Lumex, Russia) equipped with an autosampler and hollow cathode lamps. Calibration curves were constructed using oil-based single metal standards $(\mathrm{Mn}, \mathrm{Co}, \mathrm{Ni}, \mathrm{Cu}, \mathrm{Zn})$ manufactured by Specpure ${ }^{\circledR}$ and CONOSTAN ${ }^{\circledR}$. Both samples and standards were dissolved and analyzed in toluene. ${ }^{1} \mathrm{H}$ NMR spectra were recorded on an AVANCE II TM-500 spectrometer (Bruker, Germany) at $298 \mathrm{~K}$. Chemical shifts were reported relative to the residual signal of deuterated solvent.

Mass spectra were registered using an UltraFlex III MALDI-TOF/TOF mass spectrometer (Bruker, Germany) with a $355 \mathrm{~nm}$ Nd:YAG laser in a linear mode. The accelerating voltage was $25 \mathrm{kV}$, and the acceleration delay was $30 \mathrm{~ns}$. On an MTP AnchorChip ${ }^{\mathrm{TM}}$ target, 
$0.5 \mu \mathrm{L}$ of $1 \%$ solution of the matrix (1,8,9-trihydroxyanthracene) in acetonitrile and the same volume of $\sim 0.1 \%$ solution of the sample in chloroform were sequentially spotted. Spectra were acquired at 150 shots per spectrum. Data analysis was performed using FlexAnalysis 3.0 software. Positively charged ions were analyzed. The porphyrins were identified by the signals of their molecular cation radicals $\left([\mathrm{M}]^{+\bullet}\right)$.

The dichloromethane extracts of the reaction mixtures were analyzed on an AutoSystem XL/TurboMass Gold chromatomass spectrometer (PerkinElmer Instruments, Norwolk, USA) equipped with an Elite-5MS capillary column (30 m length $\times 0.25 \mathrm{~mm}$ I.D. $\times 0.25 \mu \mathrm{m}$ stationary phase thickness). The temperature regime of the column was as follows: $50^{\circ} \mathrm{C}$ for the initial $10 \mathrm{~min}$ then a programmed increase at $10{ }^{\circ} \mathrm{C} / \mathrm{min}$ to $250{ }^{\circ} \mathrm{C}$. The carrier gas (helium) pressure was set to $20 \mathrm{kPa}$; the ion source temperature was $220^{\circ} \mathrm{C}$; the ionization energy was $70 \mathrm{eV}$; the volume injected was $0.5 \mu \mathrm{L}$. Retention times of 2mercaptoethanol and 2,2'-dithiobisethanol were 4.18 and $15.60 \mathrm{~min}$, respectively. Both compounds were identified on total ion current chromatograms by their mass spectra (electron ionization, EI), matching with reference mass spectra in the NIST database. The main peaks for 2-mercaptoethanol: $\mathrm{m} / z 78\left(57 \%\right.$, [M] $\left.{ }^{+\bullet}\right), 60(100 \%), 47(69 \%), 31(46 \%)$; for 2,2'-dithiobisethanol: $m / z 154\left(56 \%,[\mathrm{M}]^{+\bullet}\right), 110(18 \%), 92(100 \%), 79(53 \%), 64(42 \%)$, $45(94 \%)$.

\section{Conclusions}

Sulfuric acid demetallization of high-purity petroleum vanadyl porphyrins diluted with chloroform allows us to obtain free porphyrin bases of high spectral purity as assessed by UV-Vis and mass spectrometric measurements. The resulting porphyrin bases can be readily complexed with divalent cations of transition metals, such as $\mathrm{Co}, \mathrm{Ni}, \mathrm{Cu}$, and Zn. According to FT-IR and MALDI-TOF mass spectroscopic analysis, complexation with these metals, introduced into the reaction mixture as acetate salts, occurs without evident formation of side products. Complexation with $\mathrm{Mn}^{2+}$ is accompanied by oxidative cleavage of the exocyclic ring of the most abundant DPEP porphyrins, thus resulting in dramatic change in petroporphyrin component composition. Even more profound oxidation with tetrapyrrole macrocycle destruction occurred during our failed attempts to produce iron porphyrins. In the Merox reaction with 2-mercaptoethanol, copper petroleum porphyrins exhibited the highest catalytic activity relative to vanadyl, manganese, cobalt, nickel, and zinc complexes. In the literature, cobalt porphyrins and phthalocyanines are regarded the most active catalyst for the Merox process.

Author Contributions: Conceptualization, M.Y. and N.M.; methodology, N.M., D.T., D.M. and L.M.; validation, D.T., L.M. and N.M.; formal analysis, N.M.; investigation, D.T., L.M., E.T. and D.M.; resources, M.Y., S.Y. and D.T.; writing—original draft preparation, N.M. and D.T.; writing-review and editing, M.Y. and S.Y.; visualization, N.M., D.T. and S.Y.; supervision, M.Y.; project administration, M.Y. and S.Y.; funding acquisition, M.Y. All authors have read and agreed to the published version of the manuscript.

Funding: This research was funded by the Russian Science Foundation, grant number 19-13-00089.

Acknowledgments: The authors are grateful to the staff of the Distributed Spectral-Analytical Center of Shared Facilities for the Study of Structure, Composition, and Properties of Substances and Materials of the Federal Research Center of Kazan Scientific Center of the Russian Academy of Sciences for their research and assistance in discussing the results.

Conflicts of Interest: The authors declare no conflict of interest. The funders had no role in the design of the study; in the collection, analyses, or interpretation of data; in the writing of the manuscript; or in the decision to publish the results.

\section{References}

1. Sorokin, A.B. Phthalocyanine metal complexes in catalysis. Chem. Rev. 2013, 113, 8152-8191. [CrossRef]

2. Nakagaki, S.; Ferreira, G.K.B.; Ucoski, G.M.; De Freitas Castro, K.A.D. Chemical reactions catalyzed by metalloporphyrin-based metal-organic frameworks. Molecules 2013, 18, 7279-7308. [CrossRef] [PubMed] 
3. Barona-Castaño, J.C.; Carmona-Vargas, C.C.; Brocksom, T.J.; De Oliveira, K.T.; Graça, M.; Neves, P.M.S.; Amparo, M.; Faustino, F. Porphyrins as catalysts in scalable organic reactions. Molecules 2016, 21, 310. [CrossRef] [PubMed]

4. Che, C.-M.; Huang, J.-S. Metalloporphyrin-based oxidation systems: From biomimetic reactions to application in organic synthesis. Chem. Commun. 2009, 27, 3996-4015. [CrossRef] [PubMed]

5. Mironov, N.A.; Milordov, D.V.; Abilova, G.R.; Yakubova, S.G.; Yakubov, M.R. Methods for studying petroleum porphyrins (review). Petrol. Chem. 2019, 59, 1077-1091. [CrossRef]

6. Zhao, X.; Xu, C.; Shi, Q. Porphyrins in Heavy Petroleums: A Review. In Structure and Modeling of Complex Petroleum Mixtures. Structure and Bonding; Xu, C., Shi, Q., Eds.; Springer: Cham, Switzerland, 2015; Volume 168, pp. 39-70.

7. Ledoux, M.J.; Hantzer, S. Hydrotreatment catalyst poisoning by vanadium and nickel porphyrin: ESR and NMR. Catal. Today 1990, 7, 479-496. [CrossRef]

8. Li, X.; Peng, X.H.; Zheng, B.D.; Tang, J.; Zhao, Y.; Zheng, B.Y.; Ke, M.R.; Huang, J.D. New application of phthalocyanine molecules: From photodynamic therapy to photothermal therapy by means of structural regulation rather than formation of aggregates. Chem. Sci. 2018, 9, 2098-2104. [CrossRef] [PubMed]

9. Wöhrle, D.; Schnurpfeil, G.; Makarov, S.G.; Kazarin, A.; Suvorova, O.N. Practical applications of phthalocyanines-From dyes and pigments to materials for optical, electronic and photo-electronic devices. Macroheterocycles 2012, 5, 191-202. [CrossRef]

10. Zhang, Y.; Lovell, J.F. Recent applications of phthalocyanines and naphthalocyanines for imaging and therapy. WIREs Nanomed. Nanobiotechnol. 2017, 9, e1420. [CrossRef]

11. Mironov, N.; Milordov, D.; Abilova, G.; Tazeeva, E.; Yakubova, S.; Yakubov, M. Preparative-scale purification of petroleum vanadyl porphyrins by sulfuric acid loaded macroporous silica. J. Porphyr. Phthalocyanines 2020, 24, 528-537. [CrossRef]

12. Rytting, B.M.; Singh, I.D.; Kilpatrick, P.K.; Harper, M.R.; Mennito, A.S.; Zhang, Y. Ultrahigh-purity vanadyl petroporphyrins. Energy Fuel 2018, 32, 5711-5724. [CrossRef]

13. Hu, X.; Huang, Z.; Gu, G.; Wang, L.; Chen, B. Heterogeneous catalysis of the air oxidation of thiols by the cobalt porphyrin intercalated into a phosphatoantimonic acid host. J. Mol. Catal. A Chem. 1998, 132, 171-179. [CrossRef]

14. Hassanein, M.; Gerges, S.; Abdo, M.; El-Khalafy, S. Catalytic activity and stability of anionic and cationic water soluble cobalt(II) tetraarylporphyrin complexes in the oxidation of 2-mercaptoethanol by molecular oxygen. J. Mol. Catal. A Chem. 2005, 240, 22-26. [CrossRef]

15. Ehsani, M.R.; Safadoost, A.R.; Avazzadeh, R.; Barkhordari, A. Kinetic study of ethyl mercaptan oxidation in presence of Merox catalyst. Iran. J. Chem. Chem. Eng. 2013, 32, 71-80.

16. Akhmadullin, R.M.; Gubaidullin, A.T.; Kharlampidi, K.E.; Kurbankulov, S.R.; Nigmatullin, T.F.; Dao, M.U.; Khamidullin, R.F.; Akhmadullina, A.G.; Vasseghian, Y.; Hoang, H.Y. Bivalent copper oligopyrocatecholate as a novel heterogeneous catalyst for the oxidative degradation of mercaptan in caustic solution: Synthesis, characterization and kinetic study. Environ. Res. 2021, in press. [CrossRef] [PubMed]

17. Xu, H.; Que, G.; Yu, D.; Lu, J.R. Characterization of petroporphyrins using ultraviolet-visible spectroscopy and laser desorption ionization time-of-flight mass spectrometry. Energy Fuel 2005, 19, 517-524. [CrossRef]

18. Zhang, Y.; Schulz, F.; Rytting, B.M.K.; Walters, C.C.; Kaiser, K.; Metz, J.N.; Harper, M.R.; Merchant, S.S.; Mennito, A.S.; Qian, K.; et al. Elucidating the geometric substitution of petroporphyrins by spectroscopic analysis and atomic force microscopy molecular imaging. Energy Fuel 2019, 33, 6088-6097. [CrossRef]

19. Mironov, N.; Milordov, D.; Tazeeva, E.; Tazeev, D.; Abilova, G.; Yakubova, S.; Yakubov, M. Impact of asphaltenes on the adsorption behavior of petroleum vanadyl porphyrins: Kinetic and thermodynamic aspects. Energy Fuel 2021, 35, 14527-14541. [CrossRef]

20. Mironov, N.A.; Abilova, G.R.; Borisova, Y.Y.; Tazeeva, E.G.; Milordov, D.V.; Yakubova, S.G.; Yakubov, M.R. Comparative study of resins and asphaltenes of heavy oils as sources for obtaining pure vanadyl porphyrins by the sulfocationite-based chromatographic method. Energy Fuel 2018, 32, 12435-12446. [CrossRef]

21. Xu, H.; Yu, D.; Que, G. Characterization of petroporphyrins in Gudao residue by ultraviolet-visible spectrophotometry and laser desorption ionization-time of flight mass spectrometry. Fuel 2005, 84, 647-652. [CrossRef]

22. Woltering, M.; Tulipani, S.; Boreham, C.J.; Walshe, J.; Schwark, L.; Grice, K. Simultaneous quantitative analysis of Ni, VO, Cu, Zn and $\mathrm{Mn}$ geoporphyrins by liquid chromatography-high resolution multistage mass spectrometry: Method development and validation. Chem. Geol. 2016, 441, 81-91. [CrossRef]

23. Zheng, F.; Hsu, C.S.; Zhang, Y.; Sun, Y.; Wu, Y.; Lu, H.; Sun, X.; Shi, Q. Simultaneous detection of vanadyl, nickel, iron, and gallium porphyrins in marine shales from the Eagle Ford formation, South Texas. Energy Fuel 2018, 32, 10382-10390. [CrossRef]

24. Swisher, J.; Hansen, N.; Maesen, T.; Keil, F.J.; Smit, B.; Bell, A.T. Theoretical simulation of n-alkane cracking on zeolites. J. Phys. Chem. C 2010, 114, 10229-10239. [CrossRef]

25. Buck, T.; Preussner, E.; Wiihrle, D.; Schulz-Ekloff, G. Influence of the metal type in the mercaptan oxidation on metal phthalocyanines. J. Mol. Catal. A Chem. 1989, 53, 17-19. [CrossRef]

26. Cheng, Z.; Song, Z.; Duan, Z.; Jiang, S.; Zhu, L.; Xia, D. Synthesis and catalytic studies of novel tetra sulfonylphenoxyls substituted $\mathrm{Co}(\mathrm{II}), \mathrm{Cu}(\mathrm{II})$, and $\mathrm{Ni}(\mathrm{II})$ phthalocyanines for the LPG sweetening. Pet. Sci. Technol. 2016, 34, 130-138. [CrossRef]

27. Loas, A.; Gerdes, R.; Zhang, Y.; Gorun, S.M. Broadening the reactivity spectrum of a phthalocyanine catalyst while suppressing its nucleophilic, electrophilic and radical degradation pathways. Dalton Trans. 2011, 40, 5162-5165. [CrossRef] [PubMed]

28. Tyapochkin, E.M.; Kozliak, E.I. Kinetic and binding studies of the thiolate-cobalt tetrasulfophthalocyanine anaerobic reaction as a subset of the Merox process. J. Mol. Cat. A Chem. 2005, 242, 1-17. [CrossRef] 